Applied Remote Sensing

Evaluation of empirical and semianalytical chlorophyll algorithms in the Ligurian and North Tyrrhenian Seas

Chiara Lapucci

Marina Ampolo Rella

Carlo Brandini

Nicolas Ganzin

Bernardo Gozzini

Fabio Maselli

Luca Massi

Caterina Nuccio

Alberto Ortolani

Charles Trees 


\title{
Evaluation of empirical and semi-analytical chlorophyll algorithms in the Ligurian and North Tyrrhenian Seas
}

\author{
Chiara Lapucci, ${ }^{\text {a,b }}$ Marina Ampolo Rella, ${ }^{\text {e }}$ Carlo Brandini, \\ Nicolas Ganzin, ${ }^{\mathrm{c}}$ Bernardo Gozzini, ${ }^{\text {a,b }}$ Fabio Maselli, ${ }^{\text {a,b }}$ Luca Massi, ${ }^{\text {d }}$ \\ Caterina Nuccio, ${ }^{d}$ Alberto Ortolani, ${ }^{a, b}$ and Charles Trees ${ }^{f}$ \\ ${ }^{a}$ Institute of BioMeteorology, National Council of Research (IBIMET-CNR), Via G. Caproni, 8, \\ 50145 Firenze, Italy \\ lapucci@lamma.rete.toscana.it \\ ${ }^{b}$ Laboratory for Meteorology and Environmental Modelling (LaMMA), \\ Via Madonna del Piano 10, 50019 Florence, Italy \\ 'IFREMER LER/PAC, La Seyne sur Mer, Toulon F-83507, France \\ ${ }^{\mathrm{d}}$ Università di Firenze, Laboratorio di Ecologia e Fisiologia Vegetale Dipartimento di Biologia \\ Evoluzionistica, Via Micheli, 1, Florence, Italy \\ ${ }^{\mathrm{e}}$ Center for Maritime Research and Experimentation (CMRE), Engineering and Technology \\ Department, Viale S. Bartolomeo 400, 19126 La Spezia, Italy \\ ${ }^{\mathrm{f}}$ Center for Maritime Research and Experimentation (CMRE), Remote Sensing Group, \\ Viale S. Bartolomeo 400, 19126 La Spezia, Italy
}

\begin{abstract}
The estimation of chlorophyll concentration in marine waters is fundamental for a number of scientific and practical purposes. Standard ocean color algorithms applicable to moderate resolution imaging spectroradiometer (MODIS) imagery, such as OC $3 \mathrm{M}$ and MedOC3, are known to overestimate chlorophyll concentration ([CHL]) in Mediterranean oligotrophic waters. The performances of these algorithms are currently evaluated together with two relatively new algorithms, OC5 and SAM_LT, which make use of more of the spectral information of MODIS data. This evaluation exercise has been carried out using in situ data collected in the North Tyrrhenian and Ligurian Seas during three recent oceanographic campaigns. The four algorithms perform differently in Case 1 and Case 2 waters defined following global and local classification criteria. In particular, the mentioned [CHL] overestimation of OC3M and MedOC3 is not evident for typical Case 1 waters; this overestimation is instead significant in intermediate and Case 2 waters. OC5 and SAM_LT are less sensitive to this problem, and are generally more accurate in Case 2 waters. These results are finally interpreted and discussed in light of a possible operational utilization of the [CHL] estimation methods. (0) 2012 Society of Photo-Optical Instrumentation Engineers (SPIE). [DOI: 10.1117/1.JRS.6.063565]
\end{abstract}

Keywords: chlorophyll; algorithm; moderate resolution imaging spectroradiometer; Tyrrhenian Sea; Ligurian Sea.

Paper 12076 received Mar. 20, 2012; revised manuscript received Aug. 9, 2012; accepted for publication Aug. 10, 2012; published online Sep. 21, 2012.

\section{Introduction}

Monitoring chlorophyll $a$ concentration ([CHL]) in marine waters is fundamental for a number of scientific and practical purposes. [CHL] estimates are essential for studying marine ecosystem dynamics, for simulating marine primary production, for evaluating the effect of environmental changes, etc. Optical remote sensing data acquired by satellite systems provide a unique opportunity to assess [CHL] over large areas in the surface layer of the ocean with high temporal frequency. ${ }^{1,2}$ The color of the ocean is in fact determined by the interactions of the incident light with substances or particles present in the water.

The most significant, optically active constituents are partitioned for convenience in three categories: phytoplankton, a group of free-floating photosynthetic organisms including other

0091-3286/2012/\$25.00 (c) 2012 SPIE 
microscopic organisms which have a minor influence on optical properties (zooplankton, heterotrophic bacteria, and viruses) $;^{3}$ non-algal particles (NAP), suspended detrital material of organic and inorganic nature; and colored dissolved organic matter (CDOM), dissolved compounds derived by the disruption of organic matter. ${ }^{3,4}$ The main phytoplankton pigment, often taken as an index of phytoplankton biomass, is chlorophyll a, which shows two absorption maxima in the blue and the red. ${ }^{5}$ Phytoplankton backscattering coefficients are extremely low. ${ }^{6}$ NAP absorption follows a decreasing exponential function of wavelength, with a consequent maximum in the blue. ${ }^{7}$ NAP backscattering is generally remarkable and is a major source of sea backscattering. ${ }^{8}$ CDOM absorption is also notable and follows a decreasing trend with wavelength, ${ }^{9}$ while CDOM backscattering is negligible.

The use of ocean color to estimate [CHL] in surface waters is complicated by interactions among optically active seawater constituents. The partly common absorption and scattering properties of the three main constituents, in fact, tend to create ambiguous spectral situations especially when they are at similar low concentrations in seawater. ${ }^{10}$ This issue can be dealt with by applying the optical classification scheme introduced by Morel and Prieur ${ }^{4}$ and Gordon and Morel. ${ }^{11}$ The classification is based on the role of phytoplankton in determining the optical properties of the waters, that are partitioned into Case 1 or Case 2.

By definition, Case 1 waters are those waters in which phytoplankton, with their accompanying and covarying retinue of material of biological origin, are the principal agents responsible for variations in optical properties of the water. Case 2 waters are influenced not only by phytoplankton and related particles (namely related colored dissolved organic matter and detritus degradation products), ${ }^{12}$ but also, by NAP and CDOM, that vary independently of phytoplankton. ${ }^{3,13}$ The variegation within Case 2 waters is large, because the concentrations as well as the specific inherent optical properties of CHL, NAP, and CDOM are subject to potentially large and independent variations. ${ }^{14}$

The relationships between optical substances on which this classification is based have important consequences on the functioning of empirical and semi-empirical algorithms which estimate [CHL] from data taken by multi-spectral, narrow-band satellite sensors such as SeaWiFS and moderate resolution imaging spectroradiometer (MODIS). Most of these algorithms, in fact, use the single-variable approach, which fails in Case 2 waters, where the estimation of $[\mathrm{CHL}]$ requires a more thorough characterization of all optically active seawater components. ${ }^{15}$ Moreover, these algorithms are only as good as the in situ and satellite observations they are based on, and also depend on how representative these data are of the environment or bio-optical provinces where the algorithms are to be applied. ${ }^{16}$ Consequently, algorithms which have been developed for global applications are generally inaccurate in Case 2 waters, as well as in Case 1 waters with area-specific optical signatures. ${ }^{17,18}$

Several evaluation and validation exercises carried out in various regional oceanic areas have confirmed that new revised algorithms are necessary. ${ }^{15,19,20}$ This is typically the case for the Mediterranean Basin, the optical properties of which are peculiar compared to those of other seas. Lee and $\mathrm{Hu}^{21}$ suggested that this peculiarity is due to the presence of an unusually high CDOM content. This hypothesis was supported by Morel and Gentili, ${ }^{22}$ who showed that the absorption coefficient of CDOM at $443 \mathrm{~nm}$ is about twice the value observed in the nearby Atlantic Ocean at the same latitude with similar trophic conditions. As a consequence, in the Mediterranean Sea, global algorithms generally lead to a significant overestimation of [CHL]. ${ }^{23-27}$

The current work focuses on this issue concerning the Ligurian and North Tyrrhenian Seas. This is the study area of the EU funded Sistema integrato per il MOnitoraggio e il controllo dell'ambiente MARino (MOMAR) project (http://www.mo-mar.net/), which coincides with the Cetacean Sanctuary and includes oceanic and neritic waters and the outlets of important rivers: Arno, Serchio, and Magra. Such environmental differentiation adds to the mentioned Mediterranean peculiarity and renders the area particularly critical for the application of [CHL] algorithms. The paper evaluates the local performances of a set of empirical and semi-analytical algorithms using a data set of seawater samples and MODIS imagery taken during the last three years. Four algorithms are considered which have a specific interest for the study area. The global OC $3 \mathrm{M}^{28,29}$ and $\mathrm{MedOC}^{30}$ algorithms (regionally tuned to the North Western Mediterranean Sea), which are commonly applied in the study area despite the fact that they are only suited for Case 1 waters. ${ }^{25,31,32}$ OC 5 algorithm, which, although more specific 
for Atlantic waters (Bay of Biscay and the English Channel), performs well also in other areas. $^{33-35}$ The semi-analytical SAM LT algorithm ${ }^{36}$ is locally tuned for the coastal Ligurian and North Tyrrhenian Sea areas.

The paper is organized as follows. First, the basic features of the four algorithms examined are briefly introduced. The main characteristics of the study area are then presented, followed by a description of the collection and analysis of the seawater samples. Next, the methodologies used to assess the performances of the four [CHL] algorithms in Case 1 and Case 2 waters are presented. Finally, the results obtained are illustrated and discussed.

\section{Chlorophyll Retrieval Algorithms Examined}

There are many examples of both empirical and semi-analytical algorithms applicable to optical satellite imagery for chlorophyll concentration retrieval: ${ }^{25,30}$ the following paragraphs describe the basic features of the four algorithms currently examined.

\section{$2.1 \mathrm{OC} 3 \mathrm{M}$ and MedOC3}

The OC3M algorithm is a member of the OC* family of algorithms. They were developed globally using an in situ data set consisting of both Case 1 and Case 2 waters with the approximate range of $0.01<[\mathrm{CHL}]<75 \mathrm{mg} \mathrm{m}^{-3}$. The algorithm, which is based on a Case 1 assumption, is a fourth degree polynomial regression between log-transformed [CHL] and log-transformed maximum band ratio (MBR) of remote sensing reflectances $(\operatorname{Rrs}):^{29}$

$$
[\mathrm{CHL}]=10^{C_{0}+C_{1} R+C_{2} R^{2}+C_{3} R^{3}+C_{4} R^{4}}, \quad \text { where } R=\log _{10}\left(\frac{\operatorname{Rrs} 443>\operatorname{Rrs} 488}{\operatorname{Rrs} 547}\right) .
$$

The blue/green ratio has the advantage of normalizing internal and external conditions (scattering coefficient variability, geometry, incident radiance at the surface). The MBR has the additional advantage of maintaining the highest possible satellite sensor signal-to-noise ratio over a threeorders-of-magnitude in the chlorophyll concentration. ${ }^{28}$ Chlorophyll $a$ retrieved by OC $3 \mathrm{M}$ is one of the MODIS standard products (Level 2), distributed by the NASA on the Ocean Color website (http://oceancolor.gsfc.nasa.gov/). The OC3M coefficients used are OC3Mv5, $v 5$ standing for the version of the NOMAD (NASA bio-Optical Marine Algorithm Data set) dataset used to derive the algorithms. $^{37}$ NOMAD dataset includes coincident observations of spectral water-leaving radiances, surface irradiances, diffuse downwelling tion coefficients, and chlorophyll $a$ concentrations, along with relevant metadata. The v5 coefficients are unpublished results provided by J. E. O'Reilly (lead for the OC2, OC3M, and OC4 algorithms).

The MedOC3 bio-optical algorithm ${ }^{30}$ is based, like OC3M, on a fourth-power polynomial regression between log-transformed [CHL] and log-transformed MBR [Eq. (1)]. This algorithm was calibrated on a representative open-water bio-optical dataset collected in the Mediterranean area, and is declared to match the requirements of unbiased satellite chlorophyll estimation. ${ }^{30}$ The coefficients used in the OC3M and MedOC3 algorithms are reported in Table 1.

\section{$2.2 O C 5$}

The OC5 algorithm was proposed by Ifremer (Institut Français de Recherche pour l'Exploitation durable de la Mer). ${ }^{33}$ This algorithm was developed to correct for the [CHL] overestimation brought by the standard OC3M algorithm specifically in the Bay of Biscay and the English

Table 1 Coefficients used for the OC3M and MedOC3 algorithms.

\begin{tabular}{llcccr}
\hline \hline & \multicolumn{1}{c}{$\mathrm{C}_{0}$} & $\mathrm{C}_{1}$ & $\mathrm{C}_{2}$ & $\mathrm{C}_{3}$ & $\mathrm{C}_{4}$ \\
\hline Oc3M & 0.225400 & -2.63540 & 1.80710 & 0.0063000 & -1.29310 \\
MedOC3 & 0.380 & -3.688 & 1.036 & 1.616 & -1.328 \\
\hline \hline
\end{tabular}


Channel coastal areas. In these areas, [CHL] estimated by OC3M appeared to be higher than the concentrations actually found by in situ measurements, particularly from late summer to early spring, when optical properties are dominated by CDOM and NAP. ${ }^{33}$ The effect of NAP backscattering on the ratios used as inputs in OC3M is revealed by the $547 \mathrm{~nm}$ channel, whereas possible atmospheric over-correction and the absorption of CDOM and non-algal particles are indicated by the $412 \mathrm{~nm}$ channel. Based on a dataset originally collected in the English Channel and on the continental shelf of the Bay of Biscay, to which some data on the north-western Mediterranean have been added recently, ${ }^{34}$ a parameterization of the relationship between the OC3M ratio and the $412 \mathrm{~nm}$ and $547 \mathrm{~nm}$ bands has been empirically proposed for different [CHL]. The application of a lookup table, relating triplets (OC3M band ratio, $412 \mathrm{~nm}$, and $547 \mathrm{~nm}$ bands) to [CHL], provides realistic concentration maps. ${ }^{33}$ The OC5 algorithm is expected then to perform well both in Case 1 and Case 2 waters.

\subsection{SAM LT}

The SAM LT algorithm, recently proposed by Maselli et al., ${ }^{36}$ is based on the simulation of remote sensing reflectance, $\operatorname{Rrs}_{\text {sim }}$ through the following equation:

$$
\operatorname{Rrs}_{\mathrm{sim}}=0.051 \cdot \frac{\mathrm{bbw}+[\mathrm{CHL}] \cdot \mathrm{bb}_{\mathrm{PH}}^{*}+[\mathrm{SS}] \cdot \mathrm{bb}_{\mathrm{NAP}}^{*}}{\mathrm{aw}+[\mathrm{CHL}] \cdot \mathrm{a}_{\mathrm{PH}}^{*}+[\mathrm{SS}] \cdot \mathrm{a}_{\mathrm{NAP}}^{*}+[\mathrm{YS}] \cdot \mathrm{a}_{\mathrm{YS}}^{*}},
$$

where [CHL], [SS], and [YS] are the concentrations of chlorophyll, NAP, and CDOM, respectively; $a_{w}$ is the absorption coefficient of pure seawater; $a^{*}{ }_{\mathrm{PH}}, a^{*}{ }_{\mathrm{NAP}}$, and $a^{*}{ }_{\mathrm{YS}}$ are the specific absorption coefficients of phytoplankton NAP and CDOM; $b_{\mathrm{bw}}$ is the backscattering coefficient of pure seawater; and $b^{*}{ }_{\mathrm{bPH}}$ and $b^{*}{ }_{\mathrm{bNAP}}$ are the specific backscattering coefficients of phytoplankton and non algal particles.

The algorithm simulates a wide range of reflectances by varying the concentrations of the three optically active constituents within Eq. (2). Next, a comparative analysis of measured, $\mathrm{Rrs}_{\text {meas }}$, and simulated remote sensing reflectances, $\mathrm{Rrs}_{\text {sim }}$, is performed in order to look for a minimum of a specific error function. This function is based on the cosine of the angle between the standardized vectors of measured and simulated reflectances, $\cos \theta_{\mathrm{M}, \mathrm{S}} \cdot \cos \theta_{\mathrm{M}, \mathrm{S}}$ is equivalent to the correlation coefficient and measures the similarity in shape between the two reflectance vectors without detecting spectral amplitude differences. In this way, the algorithm is insensitive to amplitude variations of the measured reflectances, which may be due to the presence of seawater constituents with variable spectral properties and/or to inaccurate atmospheric correction of the satellite data. ${ }^{36}$ Since all specific coefficients of absorption and backscattering coefficients used in Eq. (2) are obtained from a bio-optical survey of the Ligurian and North Tyrrhenian Seas, the algorithm has intrinsically a local validity.

\section{Study Area}

The study area corresponds to the Ligurian Sea and the North Tyrrhenian Sea (Fig. 1). The Ligurian Sea is characterized by two strong and variable currents, the Western Corsican Current and the Eastern Corsican Current; the latter also affects the North Tyrrhenian Sea. These currents join and give birth to the Northern Current which describes a cyclonic circulation along the Liguro-Provençal front. Especially during the cold season, a high mesoscale activity associated with meanders in the northern current, eddy formation, or displacements in the LigurianProvençal front can be observed. ${ }^{38}$ Water exchange generally occurs from the Tyrrhenian toward the Ligurian Sea, especially in winter and spring.

The Northwestern Mediterranean Basin, which includes the Ligurian Sea and the northern part of the Tyrrhenian Sea, shows [CHL] ranging between 0.03 and $1.5 \mathrm{mg} \mathrm{m}^{-3}$ during the year. ${ }^{39,40}$ Very low concentrations are found in winter $\left(<0.08 \mathrm{mg} \mathrm{m}^{-3}\right)$, while an intense bloom occurs in spring, when the surface layer stabilizes. The spring bloom, which starts at the end of February and ends at the beginning of May, has a variable intensity from year to year, and shows the highest seasonal [CHL] values. From June to August, [CHL] is lower than in winter. ${ }^{1}$ Sometimes an intense autumn bloom occurs, when the thermocline is 


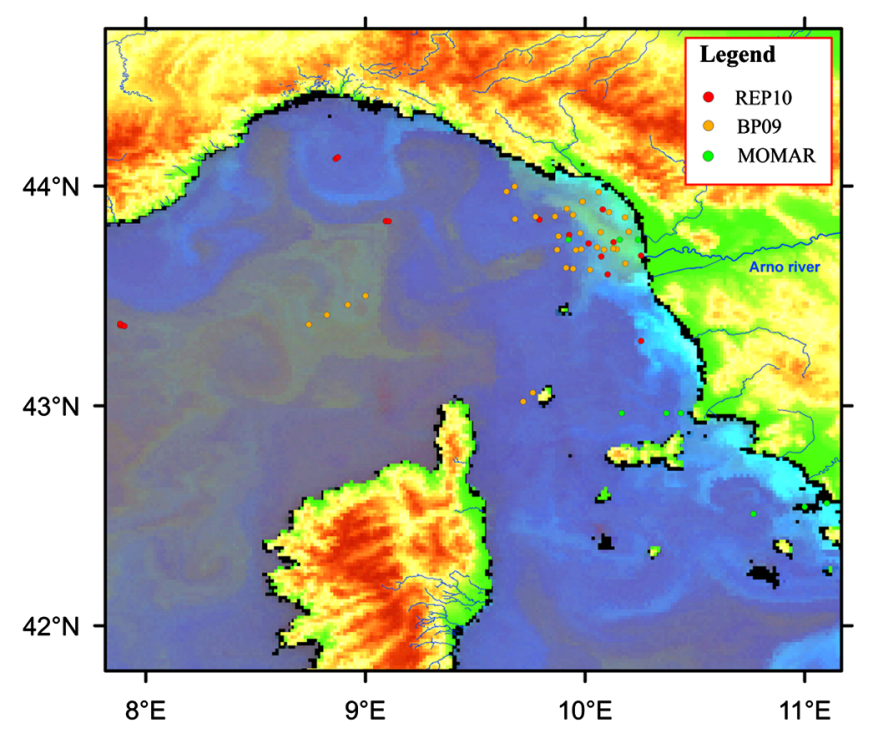

Fig. 1 Color map of the study area showing on the sea a color composition (RGB = bands 9, 11 and 14) of a MODIS image (March 17, 2009) taken during the first study campaign (BP09), with indication of all sample points, and on the land a chromatic representation of orography with the main rivers superimposed.

progressively eroded. ${ }^{1}$ The annual cycle of phytoplankton biomass can therefore be characterized by two maxima in spring and in fall, or by an unique bloom from fall to late spring. ${ }^{39}$ In the northern part of this sea, [CHL] reaches up to $1.5 \mathrm{mg} \mathrm{m}^{-3}$ while in the southern portion [CHL] does not exceed $1 \mathrm{mg} \mathrm{m}^{-3}$ during late winter-beginning of spring maxima. Near the coast and in the largest river mouths [CHL] can be higher than $5 \mathrm{mg} \mathrm{m}^{-3} .{ }^{41}$ In these eutrophic areas [CHL] rarely drops below $1 \mathrm{mg} \mathrm{m}^{-3}$, and the regularity of the phytoplankton temporal cycle can fail. ${ }^{39}$

In summary, the study area includes both neritic (the aquatic environment overlying the sublittoral zone, 0 to $200 \mathrm{~m}$ ) and oceanic environments. Even neritic zones generally behave like Case 1 waters. ${ }^{39}$ Case 2 waters prevail in coastal areas, especially near sandy littorals and river mouths where the suspended detrital particles and dissolved organic matter are determinant for light attenuation. In particular, turbid waters can be found frequently at the Arno river plume, which runs towards north along the coast.

The water optical characteristics in the whole study area are complex, because in this area phytoplankton absorption coefficients at $440 \mathrm{~nm}$ are similar to those of NAP and CDOM; phytoplankton is generally not the predominant optical component; and [CHL] is significantly correlated with the concentrations of the other optically active constituents. ${ }^{3,42}$ Further details on the optical properties of the area can be found in Nuccio et al. ${ }^{42}$

\section{Collection and Analysis of In Situ Data}

\subsection{Collection of Sea Data}

Three oceanographic cruises were conducted in the NorthTyrrhenian and Ligurian Seas (Fig. 1): two were carried out by NURC (NATO Undersea Research Centre) on board NR/V Alliance, in March 2009 (BP09), and in August through September 2010 (REP10); and one was carried out by Laboratorio di Ecologia e Fisiologia Vegetale, Dipartimento di Biologia Evoluzionistica, University of Florence, in July 2010, within the framework of the EU funded MOMAR project.

Table 2 summarizes the main features of the three oceanographic campaigns. BP09 and REP10 were conducted in the North Tyrrhenian and Ligurian Seas, with focus on the Arno river mouth and across the front of the Northern Current areas. In addition, sampling was also performed off the French coast nearby the Boussole Optical Buoy (http://www.obs-vlfr .fr/Boussole/). The MOMAR campaign concerned three transects perpendicular to the Tuscany 
Table 2 Main features and relevant [CHL] statistics of the three oceanographic campaigns currently considered.

\begin{tabular}{|c|c|c|c|c|c|c|}
\hline Campaign & Period & $\begin{array}{l}\text { Number of } \\
\text { stations }\end{array}$ & $\begin{array}{c}\text { [CHL] } \\
\text { Average } \\
\left(\mathrm{mg}^{-3}\right) \\
\left.\mathrm{mg} \mathrm{m}^{-3}\right)\end{array}$ & $\begin{array}{c}{[\mathrm{CHL}]} \\
\text { Standard } \\
\text { deviation } \\
\left(\mathrm{mg} \mathrm{m}^{-3}\right)\end{array}$ & $\begin{array}{c}{[\mathrm{CHL}] \text { minimum }} \\
\left(\mathrm{mg} \mathrm{m}^{-3}\right)\end{array}$ & $\underset{\left(\mathrm{mg} \mathrm{m}^{-3}\right)}{[\mathrm{CHL}] \text { maximum }}$ \\
\hline $\begin{array}{l}\text { BP09 } \\
\text { (NURC) }\end{array}$ & 14-23 March 2009 & 33 & 1.011 & 0.712 & 0.396 & 2.837 \\
\hline $\begin{array}{l}\text { MOMAR } \\
\text { (University } \\
\text { of Florence) }\end{array}$ & 19-22 July 2010 & 9 & 0.126 & 0.076 & 0.045 & 0.311 \\
\hline $\begin{array}{l}\text { REP10 } \\
\text { (NURC) }\end{array}$ & $\begin{array}{c}19 \text { August-3 } \\
\text { September } 2010\end{array}$ & 21 & 0.298 & 0.536 & 0.050 & 1.899 \\
\hline
\end{tabular}

coastline: three stations, at 3 (coastal), 10, and $30 \mathrm{~km}$ from the coastline were sampled for each transect (Fig. 1).

For most of these stations water samples were taken using Niskin bottles at different depths, from surface to around $100 \mathrm{~m}$, according to the water column conditions: after collecting one surface sample, deeper sample depths were chosen taking into consideration seafloor depth and fluorescence peak depth. In all cases, however, only surface samples were taken into consideration for comparison with satellite [CHL] estimates.

Optical measurements were collected only when the atmospheric conditions were appropriate. Reflectance spectra were thus measured for 23 samples of BP09, 9 samples of MOMAR and 15 samples of Rep10. In the BP09 and Rep10 cruises reflectance measurements were taken by a Satlantic Hyper Pro II radiometer package. This is a free-falling profiler configured with two different hyper spectral radiometric sensors measuring downwelling irradiance and upwelling radiance, and a reference radiometric 'in air' solar irradiance sensor. ${ }^{43}$ The water-leaving radiance at nadir was obtained from the below surface radiance as: ${ }^{3}$

$$
L_{w}=L_{u}\left(0^{-}\right) \frac{1-\rho(\theta)}{n},
$$

where $\rho(\theta)$ is the Fresnel reflection coefficient for the water-air interface, and $n$ is the refractive index of seawater. For the comparison with satellite data, remote sensing reflectance (Rrs) was obtained from $L_{w}$ values using the formula: ${ }^{4}$

$$
\operatorname{Rrs}=\frac{L_{w}}{E_{s}} .
$$

Rrs values can be directly compared with the MODIS products. ${ }^{44}$

In the MOMAR cruises a calibrated spectroradiometer (LI-1800 UW, LI-COR instruments) was used to determine spectral irradiance at discrete depths determined by an external sensor. Downward and upward spectral irradiances were measured over the 350 to $750 \mathrm{~nm}$ range with a resolution of $1 \mathrm{~nm}$. The measurements were taken around local noon with two separate casts; if necessary, the data were corrected for changes in surface solar irradiance during the measurement. Solar irradiance was monitored by a cosine collector PAR sensor (PNF, Biospherical Instrument, or LI-192SA, LI-COR Instruments). The whole collection and processing methodology was carried out following Morel et al. ${ }^{45}$ Irradiance reflectance was finally converted to Rrs by the method described in Lee et al. ${ }^{46}$

\subsection{Determination of [CHL]}

The collected water samples were analyzed for chlorophyll $a$ concentration by high-performance liquid chromatography (HPLC) method in the case of the BP09 and MOMAR campaigns, and by spectrofluorometric method in the case of the REP10 campaign. More particularly, the BP09 and REP10 samples were analyzed following the procedure protocol defined in Mueller et al. ${ }^{47}$ 
Samples were collected on GF/F filters, $25 \mathrm{~mm}$ for spectrofluorescence and $47 \mathrm{~mm}$ for HPLC. The BP09 samples were stored in liquid nitrogen and then shipped to Analytical Services HPLUMCES (Cambridge, MD, US) for analysis; the REP10 samples were analyzed onboard after the required extraction time ( 24 hours). Due to the proven underestimation of the real chlorophyll $a$ content caused by the spectrofluorometric method, the REP10 [CHL] data were corrected by applying the linear regression coefficients obtained from the analysis of spectrofluorometric and HPLC data of more than 250 samples taken by NURC. ${ }^{48}$

The MOMAR samples were analyzed according to Vidussi et al ${ }^{49}$ and Barlow et al. ${ }^{50}$ after modifications of elution times and using $\beta 8$ APO CAROTENAL as an internal standard. Pigment concentrations were computed according to Mantoura and Repeta. ${ }^{51}$ [CHL] represent the sum of concentrations of chlorophyll $a$, chlorophyllide $a$, and divinyl-chlorophyll $a$ if present.

\section{Processing of Remote Sensing Data}

\subsection{Selection and Preprocessing of MODIS Images}

Twenty-four MODIS-AQUA Level-2 files, containing all or part of the study area and corresponding to the sampling days of the three cruises, were acquired from the online OBPG Data Processing System (http://oceancolor.gsfc.nasa.gov/cgi/browse.pl). All data have about $1 \mathrm{~km}^{2}$ spatial resolution at nadir, and the images are already corrected for the atmospheric effect. The following MODIS AQUA standard products were selected: Rrs_412, Rrs_443, Rrs_488, Rrs_531, Rrs_547 and Rrs_667, as inputs for OC3M, MedOC3, OC5, and SAM LT algorithms.

\subsection{Estimation and Evaluation of [CHL]}

The four algorithms described were first applied to the Rrs images in order to produce relevant [CHL] maps, which were analyzed visually. The Rrs values corresponding to all [CHL] samples were then extracted from $3 \times 3$ pixel windows centered around each station and compared to the available in situ reflectance measurements by using the mean bias and root mean square errors (MBE and RMSE, respectively).

The extracted Rrs values were converted into [CHL] estimates applying the four algorithms. In all cases regression analyses were carried out to compare the in situ and remotely sensed [CHL] estimates, and the corresponding accuracies were evaluated using various statistics. The coefficient of determination $\left(R^{2}\right)$, the intercept (a) and the slope (b) of the linear regression between measured and estimated [CHL] were computed together with the root mean square error (RMSE) and the mean bias error (MBE). The last two statistics were calculated as Eqs. (5) and (6):

$$
\begin{aligned}
\text { RMSE } & =\sqrt{\frac{\sum\left(\text { Meas }_{i}-\mathrm{Est}_{i}\right)^{2}}{N}} \\
\mathrm{MBE} & =\frac{\sum_{i=1}^{N} \mathrm{Est}_{i}-\mathrm{Meas}_{i}}{N} .
\end{aligned}
$$

A further analysis was carried out by classifying the available samples into Case 1 and 2 waters according to the two optical rules proposed by Lee and $\mathrm{Hu}^{21}$ The two rules are based on bio-optical models for Case 1 waters, developed as an inclusive and quantititive Case 1 criterion for remote sensing applications. Specifically, these rules define optical Case 1 water relations between chlorophyll a and CDOM and chlorophyll a and NAP. The two rules were applied to the sample Rrs spectra in a restrictive way, i.e., samples were considered to belong to Case 1 waters when satisfying both rules; while they were considered to belong to Case 2 waters when both these rules were not satisfied. The same objective was pursued by applying another water classification algorithm locally tuned for the Western Mediterranean basin. The 
algorithm is based on the estimation of the spectral angle similarity between sample MODIS Rrs spectra and reference spectra defined by Eq. (2) using absorption and backscattering coefficients characteristic of Western Mediterranean open waters. ${ }^{31}$ In this case also the classification of the available samples into Case 1 and 2 water types was carried out using restrictive criteria, i.e., water samples were considered to belong to Case 1 waters when the cosine of the minimum spectral angle between sample and reference Case 1 spectra was higher than 0.95 and were considered to belong to Case 2 waters when this cosine was lower than 0.6 (see Ref. 31 for details).

\section{Results}

\section{1 $[\mathrm{CHL}]$ of the Sea Samples}

The three cruises were conducted during times of the year when maximum (spring) and minimum (summer) chlorophyll concentrations generally occur in this area. ${ }^{39}$ Summary statistics of the [CHL] found during the three cruises are provided in Table 2.

The BP09 cruise was conducted in the Ligurian Sea, which normally shows oceanic water characteristics during most of the year. The campaign coincided with a typical spring algal bloom; accordingly, the highest [CHL] values (around $1.0 \mathrm{mg} \mathrm{m}^{-3}$ ) were found during this campaign in terms of all [CHL] statistics considered. The highest [CHL] $\left(2.837 \mathrm{mg} \mathrm{m}^{-3}\right)$ was found in the oceanic station located in the proximity of a mesoscale cyclonic eddy. The stations located near the Arno river plume also showed high [CHL] (still around $1.0 \mathrm{mg} \mathrm{m}^{-3}$ ), due to the influence of the river discharge.

The MOMAR campaign was conducted in three transects in front of Tuscany region during summer, when chlorophyll concentration is low even in coastal stations (around $0.1 \mathrm{mg} \mathrm{m}^{-3}$ ).

The REP10 cruise was carried out in the same area as BP09, but in summer. The largest part of the samples were taken in open sea stations and show low chlorophyll concentrations (around $0.1 \mathrm{mg} \mathrm{m}^{-3}$ ), similar to those of the MOMAR campaign. Only two stations located in front of the Arno River mouth show high [CHL] which coincides with the maximum (around $1.9 \mathrm{mg} \mathrm{m}^{-3}$ ) reported in Table 2.

\subsection{Rrs Spectra of the Sea Samples}

The per-band statistics which summarize the differences between Rrs spectra measured in situ and obtained from MODIS imagery are shown in Table 3. The largest differences are found in the blue range, and particularly in the 412 and 443 bands, which show MODIS Rrs data values greatly overestimated. Conversely, the red bands are variably underestimated. The largest of

Table 3 Results of the comparison between Rrs measured in situ and derived from MODIS imagery. The number of samples considered is 23 for BP09, 9 for MOMAR and 15 for REP10.

\begin{tabular}{lccc}
\hline \hline MODIS band & In situ Rrs average & Rrs MBE & Rrs RMSE \\
\hline 412 & 0.00440 & 0.00138 & 0.00404 \\
443 & 0.00455 & 0.00094 & 0.00334 \\
469 & 0.00466 & 0.00048 & 0.00301 \\
488 & 0.00469 & 0.00030 & 0.00276 \\
531 & 0.00331 & 0.00019 & 0.00167 \\
547 & 0.00300 & -0.00003 & 0.00147 \\
555 & 0.00273 & -0.00017 & 0.00139 \\
645 & 0.00044 & -0.00053 & 0.00233 \\
667 & 0.00028 & -0.00013 & 0.00036 \\
678 & 0.00027 & -0.00011 & 0.00034 \\
\hline \hline
\end{tabular}


the errors occur in the first two blue bands (RMSE around 0.004, MBE around 0.001), and can be mostly attributed to the strong atmospheric effect which affects these wavelengths. The negative MBE at the highest wavelengths can instead be attributed to an overcorrection of the signal for the atmospheric effect. The MODIS spectra of some samples show negative Rrs values at the lowest and highest wavelengths; these values have been retained in order to evaluate the robustness of the four algorithms to these error sources.

In general, the samples collected during the three cruises show diversified optical features which are related to relevant different eco-biological marine conditions. With regard to the BP09 data, the Rrs spectra of most samples are characterized by strong and broad maxima in the green band, related to high levels of phytoplankton biomass. The Rrs spectra of three samples show much lower maxima. Two typical examples of these spectra measured in situ and extracted from MODIS imagery are shown in Fig. 2(a); CTD13 represents the first group of samples, while CTD51 represents the latter one. CTD13 is classified as Case 2 water both by Lee and $\mathrm{Hu}^{21}$ (Lee rules) and Massi et al. ${ }^{31}$ rules (Massi rules), while CTD51 is classified as Case 1 water by Lee rules and is unclassified by Massi rules. The MODIS spectra are significanlty different from those measured in situ, especially for the blue bands. The spectral features of the first sample (CTD13) clearly reflect a high phytoplankton biomass associated to a significant presence of UV-blue absorbing material; both these features are attenuated for CTD51. Three samples were taken in the turbid waters of the Arno river plume and are similar to CTD24, [Fig. 2(a)]. These samples show a wide green Rrs maximum and are classified as Case 2 water by both Lee rules and Massi rules.

The largest part of the MOMAR samples shows Rrs spectral signatures similar to those of Fig. 2(c), indicative of the relatively low chlorophyll concentrations which are typical of this campaign. MODIS Rrs deviates from in situ Rrs all over the spectrum for the first sample (SR10) and particularly in the blue region for the second sample (T3). Both samples show a clear and wide Rrs maximum in the blue region, a sharp decrease in the green and values around zero in the red. These samples have generally low phytoplankton biomass. The SR10 sample was classified as Case 2 water by the Lee rules, and unclassified by the Massi rules; the T3 sample remained unclassified by both criteria.

The Rrs spectra taken during the REP10 cruise show more diversified spectral features [Fig. 2(b)]. Only one MODIS Rrs spectrum is shown in this case (CTD3), which has a shape very similar to that derived from in situ data, and is classified as Case 2 water by Lee rules and as Case 1 water by Massi rules. This spectrum is typical of open sea waters with $\operatorname{Rrs} 440 / \operatorname{Rrs} 412$ ratio higher than 1, likely due to the dominance of phytoplankton over CDOM and NAP; these are the most typical Case 1 water conditions. Most of the other Rep10 spectra resemble that of the CTD41 sample, which is in turn similar to those of the MOMAR cruise. All these spectra show a wide maximum in the blue region, a Rrs decrease in the green, and very low Rrs values in the red. The Rrs spectrum of the station influenced by the Arno river plume (sample CTD44) has an evident and wide green Rrs maximum and a secondary maximum in the blue band. This station is characterized by very high [CHL] $\left(1.899 \mathrm{mg} \mathrm{m}^{-3}\right)$, which is probably associated with the significant presence of NAP and CDOM. Both CTD41 and CTD44 samples are classified as Case 2 waters by Lee rules and unclassified by Massi rules.

\subsection{MODIS [CHL] Estimates}

The visual examination of the satellite derived [CHL] maps in comparison with the original Rrs images allows a preliminary assessment of the performances of the four algorithms. As an example, the four [CHL] maps obtained from the MODIS image of Fig. 1 are shown in Fig. 3(a) to 3(d): the maps correpond to a time of algal bloom during BP09 campaign (March 17, 2009). The color composition clearly shows two different types of water masses where the presence of optically active constituent is evident (Fig. 1). The former type corresponds to the open sea gyres in the north and southeast of the study area, which are characterized by green-yellow constituents; the latter type corresponds to the coastal areas of Tuscany, which show an almost white color. The Arno river plume, in the North of the Tuscany coast, shows intermediate spectral features. 


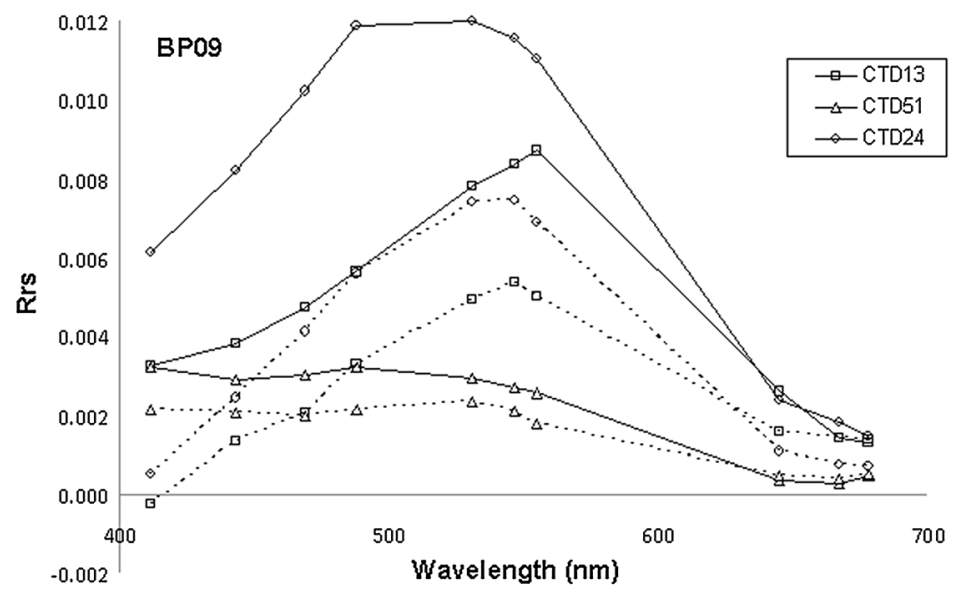

a)

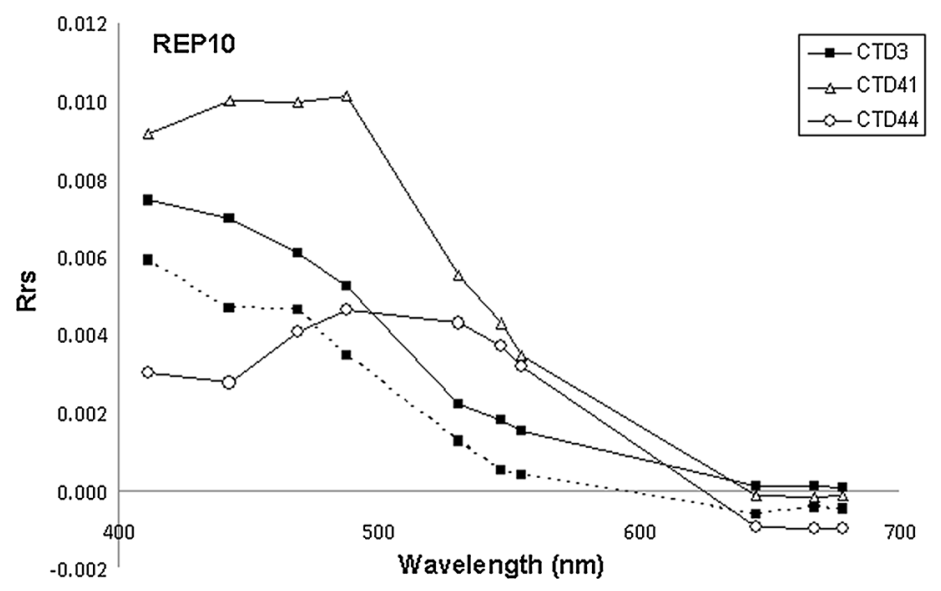

b)

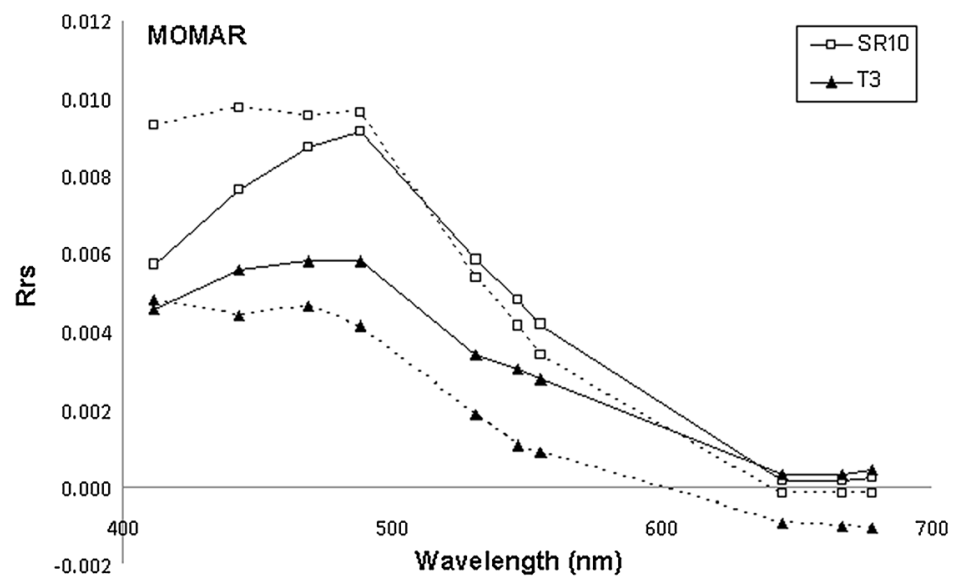

c)

Fig. 2 MODIS Rrs spectra of representative points taken during the three cruises ( $a=$ BP09, $b=$ MOMAR, $c=$ REP10). The solid lines indicate the Rrs measured in situ, the dotted lines those obtained from MODIS data.

OC3M and MedOC3 algorithms yield high [CHL] estimates for the open sea gyres in the north and southeast of the study area, as well as for most coastal zones of Tuscany [Fig. 3(a) and 3(b)]. This means that these algorithms do not differentiate green-yellow waters, likely dominated by phytoplankton, from uniformly brighter coastal waters, presumably dominated by nonorganic materials. Such a tendency is attenuated by the OC5 algorithm, which yields lower 

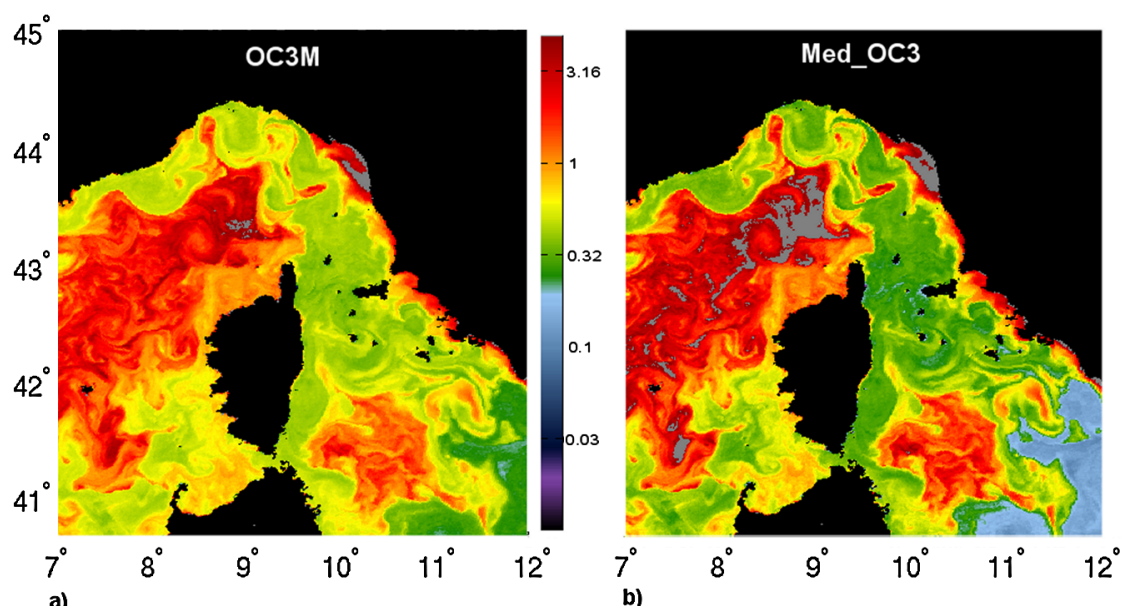

b)
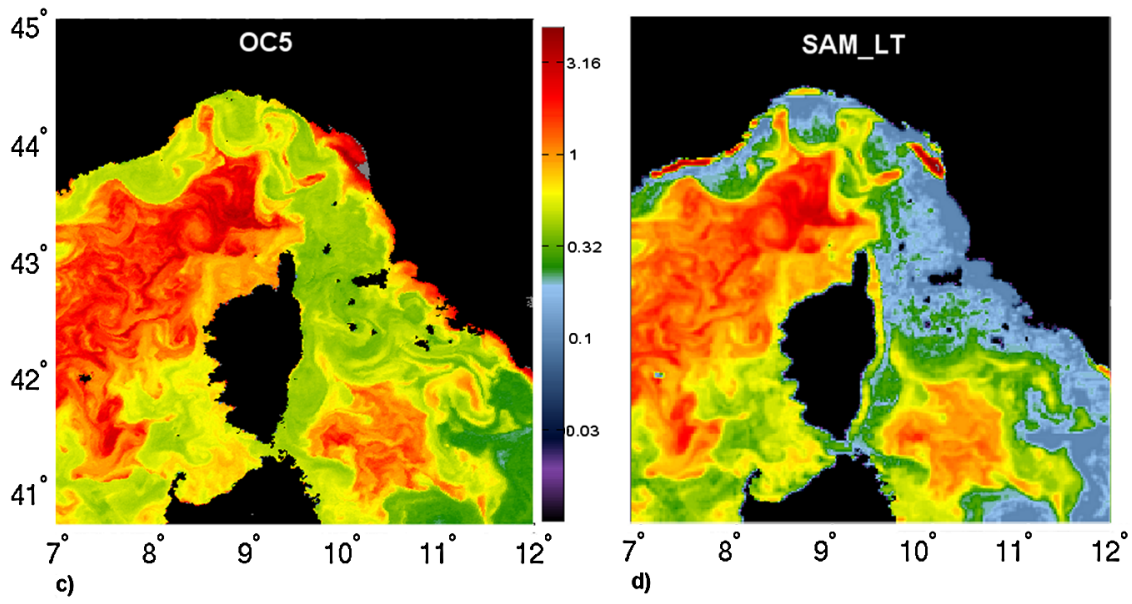

Fig. 3 Estimated [CHL] maps corresponding to the MODIS image of Fig. 1 (17 March 2009) obtained by the four algorithms considered ( $a=$ OC3M, $b=$ MedOC3, $c=$ OC5, $d=$ SAM). The scale is common for all maps.

[CHL] estimates particularly for Tuscany coastal waters [Fig. 3(c)]. The locally tuned SAM LT algorithm provides low [CHL] estimates for these areas [Fig. 3(d)], which correspond to high concentrations of non-organic materials (maps not shown).

These findings are mostly confirmed by the statistical comparison of Fig. 4(a) to 4(d). In general, the [CHL] estimates obtained by all algorithms are significantly correlated with relevant measurements at the $99 \%$ confidence level. These algorithms, however, show different levels of accuracy.

The coefficients of determination are moderate for all algorithms. The RMSE is rather high for MedOC3 and OC3M, while it is good for OC5 and SAM. The reason for this pattern can be undersood looking at MBE, which indicates that both OC3M and MedOC3 strongly overestimate [CHL]. Accordingly, the regression slopes are significantly higher than one at the $95 \%$ and 99\% confidence levels for OC3M and MedOC3, respectively. This is mostly due to the particularly great $[\mathrm{CHL}]$ overestimation of several BP09 samples.

OC5 produces a slight and not significant [CHL] underestimation, and gives good performance both in Case 1 and Case 2 waters. This algorithm overestimates [CHL] for three samples belonging to BP09 which were taken in turbid waters at the Arno river plume. The mean in situ [CHL] value of these three samples is around $1 \mathrm{mg} \mathrm{m}^{-3}$, while OC5 shows an average value around $3 \mathrm{mg} \mathrm{m}^{-3}$. The three stations show a spectral signature similar to CTD24 [Fig. 2(a)] and are classified as Case 2 waters both by Lee and $\mathrm{Hu}^{21}$ and Maselli et al. ${ }^{36}$ rules.

The SAM LT algorithm generally underestimates [CHL]. This algorithm is scarcely sensitive to low chlorophyll concentrations and gives the lowest $[\mathrm{CHL}]$ values for all stations around the 
Lapucci et al.: Evaluation of empirical and semi-analytical chlorophyll algorithms...
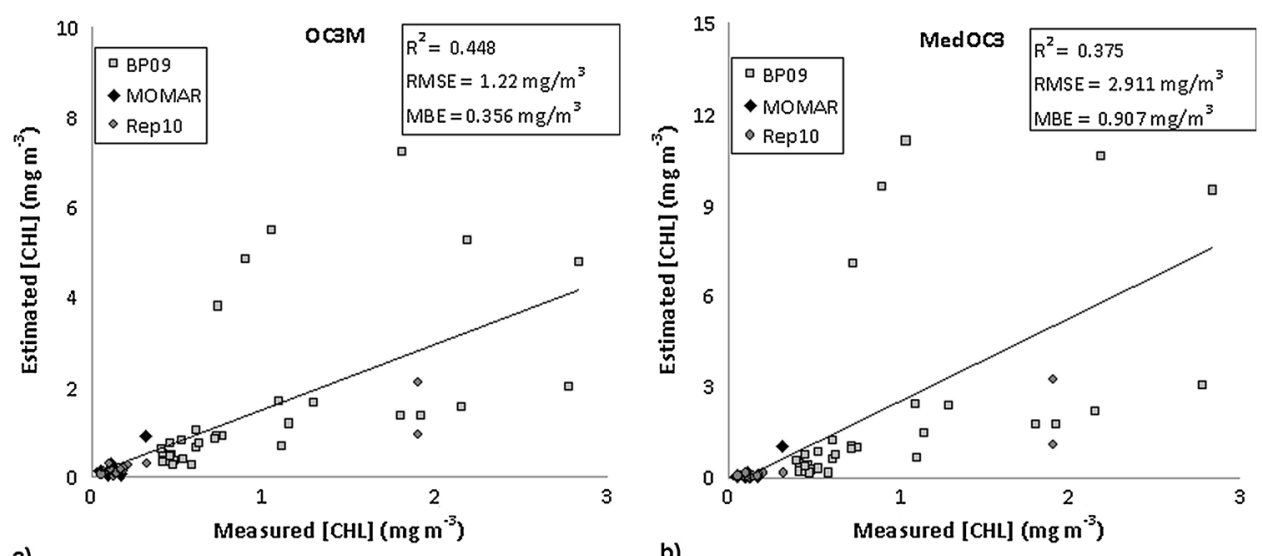

a)

b)
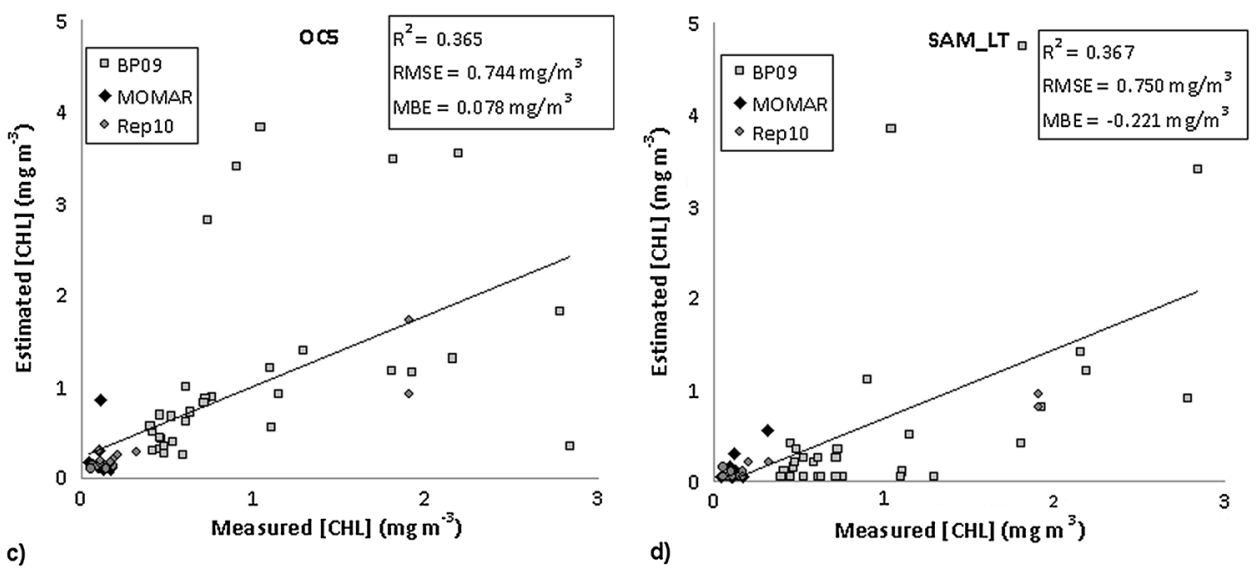

Fig. 4 Scatter plots of the $[\mathrm{CHL}]$ measured and estimated (63 samples) by the four algorithms examined, with relevant accuracy statistics. All correlations are statistically different from zero at the $99 \%$.

Boussole Optical Buoy and in the offshore stations in front of the Italian coast. In this case, [CHL] is particularly overestimated for the CTD13 and CTD22 samples, both belonging to the BP09 cruise.

Table 4 summarizes the results obtained by applying the optical classification rules of Lee and $\mathrm{Hu},{ }^{21}$ and Maselli et al., ${ }^{36}$ to the samples taken during the three cruises. The mean chlorophyll concentrations measured and estimated by the four algorithms in Case 1 and 2 waters are summarized in the bar plot of Fig. 5. The Lee and Hu criterion identifies 15 Case 1 water

Table 4 Number of samples and relevant mean $[\mathrm{CHL}]$ found by the application of the two optical classification criteria, Lee and $\mathrm{Hu}^{21}$ and Maselli et al ${ }^{36}$ to the data of the three cruises (total number of stations: 33-BP09, 9-MOMAR, 21-REP10).

\begin{tabular}{|c|c|c|c|c|c|c|c|c|}
\hline \multirow[b]{3}{*}{ Campaign } & \multicolumn{4}{|c|}{ Lee and $\mathrm{Hu}^{21}$} & \multicolumn{4}{|c|}{ Massi et al. ${ }^{31}$} \\
\hline & \multicolumn{2}{|c|}{ Case 1} & \multicolumn{2}{|c|}{ Case 2} & \multicolumn{2}{|c|}{ Case 1} & \multicolumn{2}{|c|}{ Case 2} \\
\hline & $\begin{array}{c}{[\mathrm{CHL}]} \\
\text { average } \\
\left(\mathrm{mg} \mathrm{m}^{-3}\right)\end{array}$ & $\begin{array}{c}\text { N. of } \\
\text { stations }\end{array}$ & $\begin{array}{c}{[\mathrm{CHL}]} \\
\text { average } \\
\left(\mathrm{mg} \mathrm{m}^{-3}\right)\end{array}$ & $\begin{array}{c}\text { N. of } \\
\text { stations }\end{array}$ & $\begin{array}{c}{[\mathrm{CHL}]} \\
\text { average } \\
\left(\mathrm{mg} \mathrm{m}^{-3}\right)\end{array}$ & $\begin{array}{c}\text { N. of } \\
\text { stations }\end{array}$ & $\begin{array}{c}{[\mathrm{CHL}]} \\
\text { average } \\
\left(\mathrm{mg} \mathrm{m}^{-3}\right)\end{array}$ & $\begin{array}{c}\text { N. of } \\
\text { stations }\end{array}$ \\
\hline BP09 & 0.886 & 4 & 1.016 & 17 & - & - & 1.231 & 11 \\
\hline MOMAR & 0.100 & 6 & 0.208 & 2 & 0.100 & 6 & - & - \\
\hline REP10 & 0.465 & 5 & 0.723 & 12 & 0.111 & 14 & - & - \\
\hline
\end{tabular}




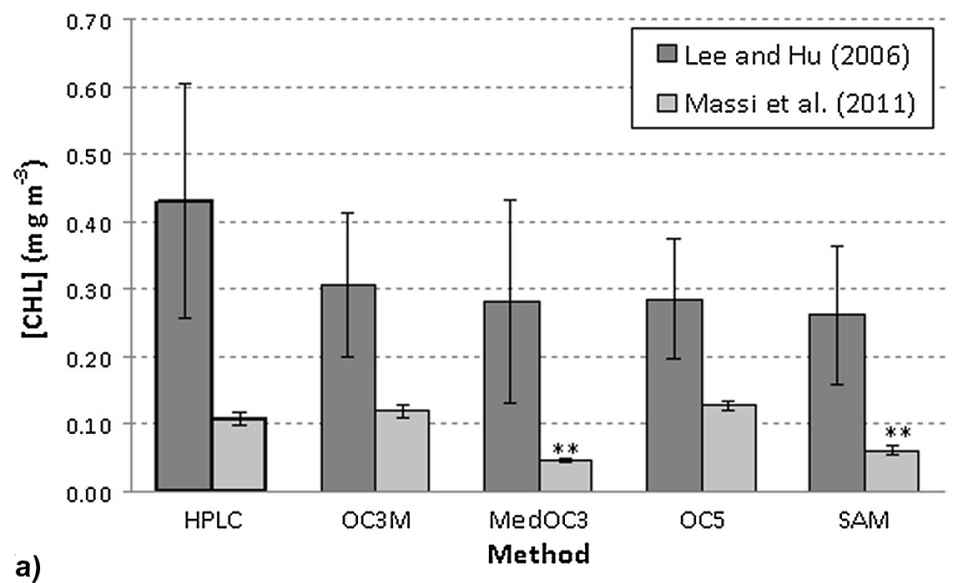

a)

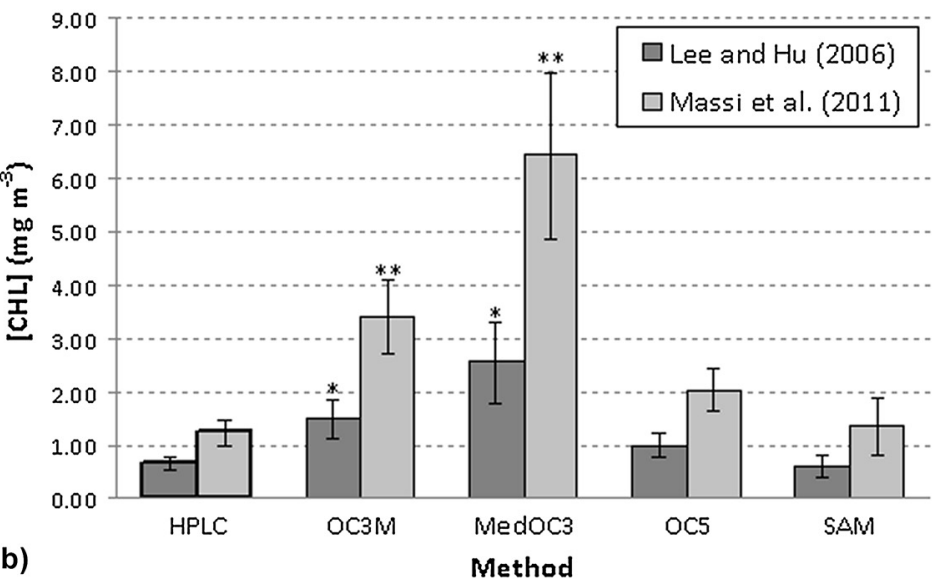

Fig. 5 Mean [CHL] measured by HPLC and estimated by the four algorithms examined for the samples classified as Case 1 (a) and Case 2 (b) waters by the optical methods of Lee and $\mathrm{Hu}^{21}$ and Maselli et al. ${ }^{36}$ (the upper bars indicate the standard errors of the measurements/estimates; $*, * *=$ estimates statistically different from measurements at the $95 \%$ and $99 \%$ confidence levels, respectively).

samples, showing a relatively high [CHL] average $\left(0.43 \mathrm{mg} \mathrm{m}^{-3}\right)$. This is mainly due to the inclusion of two samples, the first taken during the 2009 spring bloom in the Ligurian gyre [REP10 CTD51, Fig. 2(b)] and the second taken in summer 2010 near the Arno river mouth [BP09 CTD44, Fig. 2(a)]. These two samples show [CHL] close to $2 \mathrm{mg} \mathrm{m}^{-3}$ and spectral signatures atypical for Case 1 waters. Both samples, in fact, show a green Rrs peak, which is more evident for CTD44 [Fig. 2(b) and 2(a)]. The comparison with the only available Rrs spectrum measured in situ [sample CTD51, Fig. 2(a)] indicates that these spectral shapes are not due to inaccurate atmospheric correction of the MODIS data. In any case, the Rrs of these samples in the blue region is relatively high, which reduces the [CHL] estimated by all four algorithms and yields underestimated [CHL] averages. These underestimations are not statistically significant due to the large standard errors caused by averaging the [CHL] of the two anomalous samples with that of the others, which have much more oligotrophic features. If these two peculiar samples are excluded, the mean CHL concentrations become only slightly higher than those obtained by applying the locally tuned Maselli et al. ${ }^{36}$ classification. The latter classification significantly enlarges the number of samples attributed to Case 1 waters (20) while strongly restricting both [CHL] averages and dispersions. The mean [CHL] is marginally overestimated by OC $3 \mathrm{M}$ and OC5 and is significantly underestimated by MedOC3 and SAM LT.

With regard to Case 2 waters, the global Lee and $\mathrm{Hu}$ optical classification identifies more samples than that of Massi et al. (31 versus 11). The mean [CHL] of the former is slightly lower than that of the latter, but the estimation patterns of the four algorithms are very similar. OC $3 \mathrm{M}$ significantly overestimates [CHL], and this tendency is stronger for MedOC3. OC5 produces a 
slight, not significant overestimation, while SAM LT yields marginal and not significant underand overestimations depending on the use of the two water type classification methods.

\section{Discussion}

The current experimental exercise relies on a series of [CHL] measurements collected during three cruises in the Ligurian and North Tyrrhenian seas. The accuracy of these measurements is a necessary prerequisite for the correct evaluation of different remote sensing based estimation methods. As previously noted, HPLC and spectrofluorimetric methods provide different [CHL] values due to the interference of chlorophyll $b{ }^{52-55}$ The underestimation of the latter method is therefore dependent on the chlorophyll $b /$ chlorophyll $a$ concentration ratio. In the case of one campaign (REP10) this effect had to be corrected due to the lack of HPLC measurements. The correction was performed by an empirical method which was tuned on representative regional data and was demonstrated to have high statistical robustness. ${ }^{48}$ This issue must be properly taken into consideration when comparing the current results to those obtained by previous investigations in the same area. ${ }^{25,56,57}$ These studies, in fact, used the spectrofluorimetric method, which produces the mentioned variable $[\mathrm{CHL}]$ underestimation.

The in situ data collected during the three study campaigns confirm previous findings on the environmental and optical complexity of the area examined. In these waters phytoplankton is usually not the predominant optical component and shows absorption coefficients at $440 \mathrm{~nm}$ similar to those of NAP and CDOM. ${ }^{42}$ At the same time [CHL] is significantly correlated with the concentrations of the other optically active constituents. The concurrence of these two characteristics increases the optical complexity of these waters. ${ }^{3}$ This is related to the existence of diversified oceanic, neritic, and coastal water masses, and to the presence of important river plumes and mesoscale gyres in the Ligurian Sea. The operational optical classification criterion of Morel $^{58}$ puts most of these waters in an intermediate category between the two basic water types. The waters of most neritic environments belong to Case 1, but contain significant amounts of components other than phytoplankton, such as CDOM and NAP ${ }^{39,42}$ Coastal and river plume waters generally belong to Case 2, and show variable optical contributions from phytoplankton, NAP and CDOM.

The comparison between in situ and MODIS reflectance values also confirms the results of previous investigations. MODIS Rrs data are affected by errors which can be attributed to several factors, such as spatial and temporal differences in image acquisition with respect to sea data collection and geolocation and atmospheric correction inaccuracies. ${ }^{57}$ The last problem is particularly relevant in determining the largest Rrs errors found in the blue bands. These wavelengths, in fact, are most influenced by atmospheric scattering, which is difficult to simulate and remove. ${ }^{57,59}$ This problem can deteriorate the performance of all [CHL] retrieval algorithms, which heavily rely on blue Rrs values. Overcorrection of the atmospheric effect is also the likely cause of the negative Rrs values found in the red bands, where the radiometric signal is very low. This, however, has a minor effect on ocean color algorithms, which do not use, or use only marginally, red wavelengths.

The optical variegation of the study environment and the inaccuracy of the MODIS imagery differently affect the performances of the four [CHL] algorithms examined in Case 1 and 2 waters. With regard to the optical classifications applied, the global Lee and Hu algorithm is sometimes inaccurate in the identification of Mediterranean Case 1 waters. This algorithm, in fact, rejects some samples which show typical Case 1 water features and accepts a few samples with dubious optical characteristics. This is likely caused by the application of fixed thresholds to a limited number of spectral bands (4), which causes some problems when dealing with Mediterranean optical peculiarities. In order to cope with this issue, the classification proposed by Maselli et al. ${ }^{36}$ is tuned with optical measurements representative for the Western Mediterranean basin and utilizes the information of all ten MODIS bands in a fuzzy way. This allows a more flexible characterization of Case 1 and 2 waters and, in particular, a restrictive identification of samples surely belonging to the two water types.

The standard NASA algorithm for MODIS data (OC3M), based on the blue/green Rrs ratio, is known to overestimate chlorophyll concentration in Mediterranean Case 1 waters (above $70 \%$ for chlorophyll below $0.2 \mathrm{mg} \mathrm{m}^{-3}$ ). 22,24,26,29 The regionally tuned MedOC3 
algorithm, which is based on the same Rrs ratio principle, is expected to be virtually unbiased for the same waters. ${ }^{23}$ The current results only partly confirm these expectations. The samples correctly identified as belonging to Case 1 waters show low mean [CHL], which is well estimated by OC3M and underestimated by MedOC3. These findings are apparently in contrast with those of D'Ortenzio et al. ${ }^{23}$ and Volpe et al. ${ }^{25}$ who indicated that standard ocean color algorithms overestimate particularly for low $[\mathrm{CHL}]\left(<0.5 \mathrm{mg} \mathrm{m}^{-3}\right)$. The inconsistency, however, could be partly due to the previously mentioned application of different methods to determine the reference [CHL] (i.e., HPLC versus spectrofluorometer). On the other hand, the current results are in accordance with the fact that OC $3 \mathrm{M}$ and MedOC3 were calibrated only on Case 1 waters. ${ }^{29,30}$ More particularly, our results agree with the more recent findings of Morel and Gentili, who showed that the peculiar CDOM absorption which characterizes Mediterranean waters has a negligible effect when $[\mathrm{CHL}]<0.25 \mathrm{mg} \mathrm{m}^{-3} .{ }^{22}$ Consequently, in these conditions a global algorithm can work properly, while MedOC3 overcompensates the expected [CHL] overestimation. The latter algorithm, in fact, provides [CHL] estimates lower than OC3M for MBR $>1.4$, which approximately corresponds to $[\mathrm{CHL}]<0.6 \mathrm{mg} \mathrm{m}^{-3}$, and has an opposite behaviour above this [CHL] threshold.

The same behaviour explains the different performances of the two algorithms in typical Case 2 waters, which are generally characterized by [CHL] higher than $0.6 \mathrm{mg} \mathrm{m}^{-3}$. OC3M produces a remarkable [CHL] overestimation, which is even more evident with MedOC3. As expected, the two algorithms particularly fail in distinguishing the optical contributions brought by chlorophyll and NAP in proximity of the continental shelf. In these cases, in fact, the latter constituent determines decreased blue/green reflectance ratios which are interpreted as increased pigment concentrations, thus leading to notable [CHL] overestimation.

The OC5 regional algorithm appears to be the most robust in all cases, producing only a marginal $[\mathrm{CHL}]$ overestimation. Unlike OC3M and MedOC3, this algorithm was originally tuned for both oceanic and coastal French Atlantic waters, which have typical chlorophyll concentrations higher than those of North Tyrrhenian and Ligurian waters, and different optical characteristics. In spite of this, the OC5 version currently used is capable of providing quite accurate [CHL] estimates also in Mediterranean Case 1 waters. This good estimation capability can be partly attributed to the recent updating of the algorithm by the use of some data from the French Mediterranean area. ${ }^{33}$ The same capability testifies to an intrinsic robustness of the algorithm, likely linked to the consideration of additional spectral bands with respect to OC3M and MedOC3. This is in accordance with the results of Tilstone et al., ${ }^{35}$ who showed that OC5 is accurate also in the Bay of Bengal (India).

The SAM LT regional algorithm further enhances this property by considering all spectral information contained in all MODIS bands. This capacity is fundamental for the contemporaneous estimation of all three optically active seawater constituents, which is particularly effective in Italian coastal environments. In these coastal areas, which mostly correspond to Case 2 waters, the algorithm is capable of discriminating between water masses dominated by pigments and NAP, thus producing accurate [CHL] estimates. ${ }^{36}$ This algorithm, however, was tuned using spectral measurements representative only of Tuscany coastal waters, and performs less well in open sea areas having medium-low chlorophyll concentrations. Moreover, the calibration was performed using data measured by the spectrofluorimetric method, which underestimates [CHL] with respect to the currently applied HPLC procedure. This ensemble of factors could explain the low sensitivity of the algorithm to low [CHL] levels.

\section{Conclusions}

The current study presents the application of four [CHL] algorithms to MODIS imagery taken over the Ligurian and North Tyrrhenian seas. The [CHL] estimates obtained are evaluated versus in situ measurements collected during three cruises. The results of the experiment can be summarized as follows:

- The two standard ocean colour algorithms (OC3M and MedOC3), based on the blue/green MBR, overestimate [CHL] particularly in turbid, eutrophic waters. This is partly expected, since the two algorithms were calibrated in oceanic, oligotrophic waters. 
- OC5, which utilizes two additional MODIS bands, provides good [CHL] estimates in both clear and turbid waters. This is remarkable, since the algorithm calibration was mostly carried out in the Atlantic sea, taking into consideration only few Mediterranean samples.

- SAM LT, which utilizes all spectral information of MODIS imagery, yields better [CHL] estimates in turbid waters, taking into account the presence of water masses differently affected by NAP and CDOM. The current version of the algorithm, however, is poorly sensitive to low [CHL] levels which are typical of oceanic waters.

An in-depth analysis of these results suggests that the found [CHL] overestimation of standard ocean color algorithms is associated with the presence of waters with intermediate optical features, i.e., characterized by concentrations of accessory optically active constituents (mainly CDOM) higher than expected for typical Case 1 waters. In other words, the [CHL] overestimation of OC3M would not concern real Case 1 waters, but Case 1 waters with abnormal levels of CDOM and, secondarily, NAP. These waters would correspond to the so called Not Case 1 waters of Lee and $\mathrm{Hu},{ }^{21}$ that are common in the Mediterranean basin. In such conditions, regional algorithms as MedOC3 can be efficient for medium-low [CHL] levels. In contrast, both algorithms strongly overestimate [CHL] in Case 2 waters, which cover only a minor fraction of the study area but have the greatest ecological and economic importance.

OC5 appears to be more robust either in Case 1 and in Case 2 waters [Fig. (4)], this is probably related to the two additional bands that are processed in addition to ratios used as inputs in OC3M and MedOC3. Those bands are in fact sensitive to the contribution of NAP and CDOM.

The locally tuned SAM LT algorithm also utilizes more spectral information of MODIS imagery than OC $3 \mathrm{M}$ and MedOC3. The major advantages appear in Case 2 waters, especially in the three stations overestimated by OC5 and represented by BP09 CDT24, while it is scarcely sensitive to low-medium values of [CHL]. Such a limit can be explained considering that the SAM LT algorithm is based on a minimization process that also estimates NAP and CDOM and that can be less sensitive to small relative variation of [CHL], NAP, and CDOM in oligotrophic waters. This suggests that these algorithms perform differently depending on the water class, and that, however, further improvements would be necessary in light of a possible utilization for the operational monitoring of Ligurian and North Tyrrhenian waters. The most straightforward method to achieve this would be a recalibration of the MODIS OC 3M and MedOC 3 algorithms over [CHL] samples representative of various local eco-physiological ocean conditions. This would practically correspond to modifying the coefficients which modulate the effect of the spectral ratios considered. Such a modification, however, can not correct for the demonstrated incapability in distinguishing the spectral contributions of different seawater constituents, which is most evident in continental coastal waters.

With regard to OC5, its effective recalibration over a wider and more representative number of Western Mediterranean water samples is theoretically feasible, due to the nature of the algorithm. ${ }^{33}$ In the case of the semi-analytical SAM LT method, a more complex modification is needed to increase its sensitivity to small [CHL] variations which are typical of Case 1 waters. This method is in fact based on the spectral simulation of sea water characteristics, which requires the availability of representative absorption and scattering coefficients. A particular effort will therefore be directed to collect this basic information for representative Case 1 Ligurian and Tyrrhenian waters, thus improving the applicability of the method in wider oceanic areas.

\section{Acknowledgments}

The research was partly funded by the EU Project MOMAR (http://www.mo-mar.net/). Thanks are due to three anonymous JARS reviewers for their helpful comments on the first draft of the manuscript. This paper is dedicated to the memory of our coauthor, good friend, and colleague Nicolas Ganzin.

\section{References}

1. E. Bosc, A. Bricaud, and D. Antoine, "Seasonal and interannual variability un algal biomass and primary production in the mediterranean sea, as derived from 4 years of seawifs 
observations," Global Biogeochem. Cy. 18, GB1005 (2004), http://dx.doi.org/10.1029/ 2003 GB002034.

2. K. M. Krishna and S. R. Rao, "Seasonal and interannual variability of sea surface chlorophyll a concentration in the arabian sea," J. Appl. Remote Sens. 2(1), 023501 (2008), http:// dx.doi.org/10.1117/1.2837118.

3. IOCCG (International Ocean Color Coordinating Group), "Remote sensing of ocean colour in coastal, and other optically-complex, waters," in Reports of the International OceanColour Coordinating Group, No. 3, S.Sathyendranath, Ed., p. 140, IOCCG, Dartmouth, Canada (2000).

4. A. Morel and L. Prieur, "Analysis of variations in ocean color," Limnol. Oceanogr. 22(4), 709-722 (1977), http://dx.doi.org/10.4319/lo.1977.22.4.0709.

5. R. R. Bidigare, O. Schofield, and B. Prézelin, "Influence of zeaxanthin on quantum yield of photosynthesis of synechococcus clone wh7803(dc2)*," Mar. Ecol. Prog. Ser. 56, 177-188 (1989), http://dx.doi.org/10.3354/meps056177.

6. A. Bricaud, A. Morel, and L. Prieur, "Optical efficiency factors of some phytoplankters," Limno.l Oceanogr. 28(5), 816-832 (1983), http://dx.doi.org/10.4319/lo.1983.28.5.0816.

7. A. Bricaud et al., "Variations of light absorption by suspended particles with chlorophyll a concentration in oceanic (case 1) waters: analysis and implications for bio-optical models", J. Geophys. Res. 103(C13), 31033-31044 (1998), http://dx.doi.org/10.1029/98JC02712.

8. D. Stramski, A. Bricaud, and A. Morel, "Modeling the inherent optical properties of the ocean based on the detailed composition of planktonic community," Appl. Opt. 40(18), 2929-2945 (2001), http://dx.doi.org/10.1364/AO.40.002929.

9. L. Prieur and S. Sathyendranath, "An optical classification of coastal and oceanic waters based on the specific spectral absorption curves of phytoplankton pigments, dissolved organic matter, and other particulate materials," Limnol. Oceanogr. 26(4), 671-689, (1981), http://dx.doi.org/10.4319/lo.1981.26.4.0671.

10. C. D. Mobley, Chapter 1 in Light and Water: Radiative Transfer in Natural Waters, p. 592, Academic Press, San Diego (1994).

11. H. R. Gordon and A. Morel, Chapter 1 in Remote Assessment of Ocean Color for Interpretation of Satellite Visible Imagery: A Review, p. 114, Springer-Verlag, New York (1983).

12. C. D Mobley et al., "Optical modeling of ocean waters. is the case 1 -case 2 classification still useful?," Oceanography 17(2), 60-67 (2004), http://dx.doi.org/10.5670/oceanog.2004 .48 .

13. S. Sathyendranath and A. Morel, "Light emerging from the sea-interpretation and uses in remote sensing,", in Remote Sensing Applications in Marine Science and Technology, A. P.Cracknell, Ed., pp. 323-357, D Reidel Publishing Company, Dordrecht, The Netherlands (1983).

14. D. Odermatt et al., "Review of constituent retrieval in optically deep and complex waters from satellite imagery," Rem. Sens. Environ. 118, 116-126 (2012), http://dx.doi.org/10 .1016/j.rse.2011.11.013.

15. M. Darecki and D. Stramski, "An evaluation of MODIS and SeaWiFS bio-optical algorithms in the Baltic Sea," Rem. Sens. Environ. 89(3), 326-350 (2004), http://dx.doi.org/ 10.1016/j.rse.2003.10.012.

16. IOCCG (International Ocean Color Coordinating Group) "Remote sensing of inherent optical properties: fundamentals, tests of algorithms, and applications," in Reports of the International Ocean-Colour Coordinating Group, No. 5, Z. P.Lee, Ed., p. 122, IOCCG, Dartmouth, Canada (2006).

17. S. W. Bailey and P. J. Werdell, "A multi-sensor approach for the on-orbit validation of ocean color satellite data products," Rem. Sens. Environ. 102(1-2), 12-23 (2006), http://dx.doi .org/10.1016/j.rse.2006.01.015.

18. C. Santini et al., "Use of modis images to monitor water constituent concentrations in the tuscany sea," Proc. SPIE 6743, 67430M (2007), http://dx.doi.org/10.1117/12.739061.

19. D. Iluz, Y. Z. Yacobi, and A. Gitelson, "Adaptation of an algorithm for chlorophyll a estimation by optical data in the oligotrophic Gulf of Eilat," Int. J. Remote Sens. 24(5), 1157-1163 (2003), http://dx.doi.org/10.1080/0143116021000044797. 
20. A. Mendonca et al., "Evaluation of ocean color and sea surface temperature sensors algorithms using in situ data: a case study of temporal and spatial variability on two northeast Atlantic seamounts," J. Appl. Remote Sens. 4(1), 043506 (2010), http://dx.doi.org/10.1117/ 1.3328872 .

21. Z. P. Lee and C. Hu, "Global distribution of case-1 waters: an analysis from seawifs measurements," Rem. Sen. of Environ. 101(2), 270-276(2006), http://dx.doi.org/10.1016/j.rse .2005.11.008.

22. A. Morel and B. Gentili, "The dissolved yellow substance and the shades of blue in the mediterranean sea," Biogeosciences 6(11), 2625-2636 (2009), http://dx.doi.org/10.5194/ bg-6-2625-2009.

23. F. D'Ortenzio et al., "Validation of empirical seawifs algorithms for chlorophyll_a retrieval in the mediterranean sea. a case study for oligotrophic seas," Rem. Sens. Environ. 82(1), 79-94 (2002), http://dx.doi.org/10.1016/S0034-4257(02)00026-3.

24. C. Santini et al., "Calibrazioni regionali dell' algoritmo oc 3 m modis (aqua) per la stima della clorofilla," in Proc. of 9th ASITA Conf., Catania, 15-28 november, Vol. 2, pp. 1831-1836 (2005).

25. G. Volpe et al., "The colour of the mediterranean sea: global versus regional bio-optical algorithms evaluation and implication for satellite chlorophyll estimates," Rem. Sens. Environ 107(4), 625-638 (2007), http://dx.doi.org/10.1016/j.rse.2006.10.017.

26. A. Bricaud, E. Bosc, and D. Antoine, "Algal biomass and sea surface temperature in the Mediterranean Basin. Intercomparison of data from various satellite sensors, and implications for primary production estimates," Rem. Sens. Environ. 81(2-3), 163-178 (2002), http://dx.doi.org/10.1016/S0034-4257(01)00335-2.

27. H. Claustre et al., "Is desert dust making oligotrophic waters greener?," Geophys. Res. Lett. 29(10), 1469 (2002), http://dx.doi.org/10.1029/2001GL014056.

28. J. E. O'Reilly et al., "Ocean color chlorophyll algorithms for seaWiFS," J. Geophys. Res. 103(C11), 24937-24953 (1998), http://dx.doi.org/10.1029/98JC02160.

29. J. E. O'Reilly et al., "SeaWiFS Postlaunch calibration and validation analyses, part 3," NASA Tech. Memo. 2000-206892 11, S. B.Hooker and E. R. Firestone, Eds., pp. 3-8, NASA Goddard Space Flight Center, Greenbelt, Maryland (2000).

30. R. Santoleri et al., "Open waters optical remote sensing of the mediterranean seas," in Remote sensing of the European Seas, Springer, The Netherlands, pp. 103-116 (2008).

31. L. Massi et al., "Use of MODIS imagery for the optical characterization of Western Mediterranean waters," Rivista Italiana Di Telerilevamento 43(3), 19-37 (2011).

32. L. Lazzara et al., "Sub-regional patterns of primary production annual cycle in the Ligurian and North Tyrrhenian seas, from satellite data," Rivista Italiana Di Telerilevamento 42(2), 87-102 (2010).

33. F. Gohin, J. N. Druon, and L. Lampert, "A five channel chlorophyll concentration algorithm applied to seawifs data processed by seadas in coastal waters," Int. J. Rem. Sens. 23(8), 1639-166 (2002), http://dx.doi.org/10.1080/01431160110071879.

34. F. Gohin, "Annual cycles of chlorophyll-a, non-algal suspended particulate matter, and turbidity observed from space and in-situ in coastal waters," Ocean Sci. 7, 705-732 (2011), http://dx.doi.org/10.5194/os-7-705-2011.

35. G. H. Tilstone et al., "Assessment of chlorophyll-a algorithms available for seawifs in coastal areas of the bay of Bengal," Rem. Sens. Environ. 115(9), 2277-2291 (2011), http://dx.doi.org/10.1016/j.rse.2011.04.028.

36. F. Maselli et al., "Spectral angle minimization for the retrieval of optically active seawater constituents from modis data," Photogramm. Eng. Rem. Sen. 75(5), 595-605 (2009).

37. P. J. Werdell and S. W. Bailey, "An improved bio-optical data set for ocean color algorithm development and satellite data product validation," Rem. Sens. Environ. 98(1), 122-140 (2005), http://dx.doi.org/10.1016/j.rse.2005.07.001.

38. A. Bart et al., "Two-way nested model of mesoscale circulation features in the ligurian sea," Progr. Oceanogr. 66(2-4), 171-189 (2005), http://dx.doi.org/10.1016/j.pocean.2004 .07 .017 . 
39. M. Innamorati et al., "Condizioni trofiche, biomassa e popolamenti fitoplanctonici dell'alto tirreno," in Progetto Mare, Ricerca sullo stato Biologico, Chimico e Fisico dell'Alto Tirreno Toscano, pp. 103-156, Regione Toscana, Università di Firenze, Dipartimento di Biologia Vegetale (1993).

40. M. Innamorati et al., "Indagine sulle mucillaggini nel Mar Tirreno. Progetto di studio coordinato dall'icram, processi di formazione delle mucillaggini nell'adriatico e nel tirrenomat," Rapporto Finale ICRAM (2003).

41. G. Mori et al, "La Situazione delle acque del litorale Grossetano," Atti Della Società Toscana Di Scienze Naturali Residente In Pisa. Memorie. Serie A: Mineralogia, Geologi Suppl. CII, 281-291 (1995).

42. C. Nuccio et al., "Le campagne di rilevamento in situ dello stato ecologico e delle proprietà bio-ottiche," in Metodologie di monitoraggio dell'ambiente marino, pp. 431-471, A cura di Marisa Iozzelli, Regione Toscana—Lamma (2012).

43. G. Zibordi et al., "Cross-site consistent in situ measurments for satellite ocean color applications: the biomap radiometeric dataset," Rem. Sens. Environ. 115(8), 2104-2115 (2011), http://dx.doi.org/10.1016/j.rse.2011.04.013.

44. G. Pennucci et al., "Quantitative data analysis for ocean observations using hyperspectral and multispectral data provided from a multisensory system package," in Proc. of OceanObs'09: Sustained Ocean Observations and Information for Society (Annex), J.Hall, D. E. Harrison, and D. Stammer, Eds., 21-25 September 2009, ESA Publication WPP-306, Venice, Italy (2010).

45. A. Morel et al., "Optical properties of the "clearest" natural waters," Limnol. Oceanogr. 52(1), 217-229 (2007), http://dx.doi.org/10.4319/lo.2007.52.1.0217.

46. Z. P. Lee et al., "Model for the interpretation of hyperspectral remote-sensing reflectance," Appl. Opt. 33(24), 5721-5732 (1994), http://dx.doi.org/10.1364/AO.33.005721.

47. J. L. Mueller et al., Ocean Optics Protocols for Satellite Ocean Color Sensor Validation, J. L.Mueller, G. S. Fargion, and C. R. McClain, Eds., Vol. V, pp. 39-60, National Aeronautics and Space Administration, Greenbelt, MD (2003).

48. M. Ampolo Rella, "Laboratory Report," NATO UNCLASSIFIED NR-2011-001_Rev.2 (2011).

49. F. Vidussi et al., "Determination of chlorophylls and carotenoids of marine phytoplankton: separation of chlorophyll_a from divinyl-chlorophyll_a and zeaxanthin from lutein," J. Plank. Res. 18(12), 2377-2382 (1996), http://dx.doi.org/10.1093/plankt/18.12 .2377 .

50. R. G. Barlow, D. G. Cummings, and S. W. Gibb,. "Improved resolution of mono- and divinyl chlorophylls $a$ and $b$ and zeaxanthin and lutein in phytoplankton extracts using reverse phase C-8 HPLC," Mar. Ecol. Prog. Ser. 161, 303-307 (1997), http://dx.doi.org/10.3354/ meps 161303 .

51. R. F. C. Mantoura and D. J. Repeta, "Calibration methods for HPLC," in Phytoplankton Pigments in Oceanography. Guidelines to Modern Methods, S. W.Jeffrey, R. F. Mantoura, and S. W. Wright, Eds., pp. 407-428, UNESCO, Paris, France (1997).

52. C. J. Lorenzen, "Chlorophyll_b in the eastern North Pacific Ocean," Deep Sea Research Part A. Oceanographic Research Papers 28(9), 1049-1056 (1981).

53. C. Trees, M. C. Kennicut, and J. M. Brooks, "Errors associated with the standard fluorimetric determination of chlorophylls and phaeopigments," Mar. Chem. 17(1), 1-12 (1985), http://dx.doi.org/10.1016/0304-4203(85)90032-5.

54. R. F. C. Mantoura et al., "Comparison between spectrophotometric, fluorometric and HPLC methods for chlorophyll analysis," in Phytoplankton Pigments in Oceanography. Guidelines to Modern Methods, S. W.Jeffrey, R. F. Mantoura, and S. W. Wright, Eds., pp. 361-380, UNESCO, Paris, France (1997).

55. J. Neveux et al., "Comparison of chlorophyll and phaeopigment determinations by spectrophotometric, fluorometric, spectrofluorometric and hplc methods," Marine Microbial Food Webs 4(2), 217-238 (1990).

56. W. W. Gregg and N. W. Casey, "Global and regional evaluation of the SeaWiFS chlorophyll data set," Rem. Sen. of Environ. 93(4), 463-479 (2004), http://dx.doi.org/10.1016/j.rse.2003 .12 .012 . 
57. D. Antoine et al., "Assessment of uncertainty in the ocean reflectance determined by three satellite ocean color sensors (meris, seawifs and modis-a) at an offshore site in the mediterranean sea (boussole project)," J. Geophys. Res. Oceans 113, C07013 (2008), http://dx .doi.org/10.1029/2007JC004472.

58. A. Morel, "Optical modeling of the upper ocean in relation to its biogenous matter content (case 1 waters)," J. Geophys. Res. 93(C9), 10749-10768 (1988), http://dx.doi.org/10.1029/ JC093iC09p10749.

59. D. A. Siegel et al., "Atmospheric correction of satellite ocean color imagery: the black pixel assumption," Appl. Opt. 39(21), 3582-3591 (2000), http://dx.doi.org/10.1364/AO.39 .003582 .

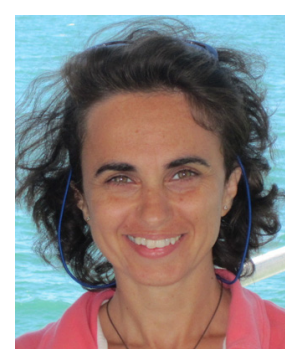

Chiara Lapucci is a researcher at the LaMMA Consortium in Florence. She graduated in biology at the University of Florence in 1994, and received her PhD from the University of Bologna in 1998. She works at the LAMMA Consortium on ocean color satellites and bio-optical remote sensing. She is experienced on in situ biogeochemical oceanographic measurements, and participated in international oceanographic campaigns in the Ligurian and North Tyrrhenian Sea. Her major interest is optimization of satellite algorithms for the estimation of bio geochemical parameters to support quantitative determination of biogeochemical sea constituents. She works in the framework of some EU (and national) projects.

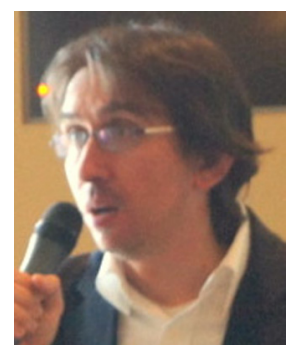

Carlo Brandini is a researcher at IBIMET CNR. He received his $\mathrm{PhD}$ in hydraulic engineering from the University of Padua in 2000. Since 2001 he collaborates with the LAMMA Consortium on numerical models for water waves propagation, ocean circulation modeling and biogeochemical implications. He works in the framework of some national and EU projects. His main interest are on extremal events dynamics, and regional/coastal operational oceanography aspects.

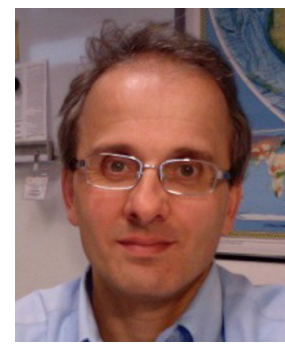

Bernardo Gozzini is senior researcher at IBIMET-CNR with experience in application of meteorology and atmospheric modelling. He is scientific director at Laboratory of environmental monitoring and modelling for the sustainable development (LaMMA) Consortium. The main sectors in which LaMMA is specialised are meteorology, climatology, geographic information systems, and geology.

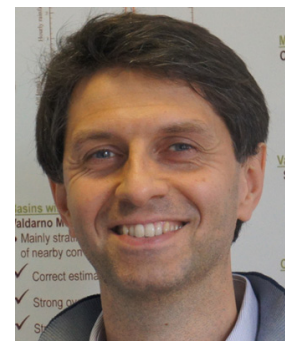

Alberto Ortolani received his master degree in physics (summa cum laude) at University of Florence, Italy with a dissertation on stellar $\mathrm{X}$-ray spectroscopy. In 2011 he got the $\mathrm{PhD}$ in "physical modelling for environment protection" at the University of Bologna, Italy with a thesis on probabilistic retrieval of atmospheric parameters from GNSS data. Since 1997 he has worked at Laboratory of environmental monitoring and modelling for the sustainable development (LAMMA) on marine remote sensing and satellite meteorology, and presently also on GNSS meteorology. From 2003 he has been a senior researcher at the Institute of Biometeorology of the National Research Council (CNR-IBIMET), operating at LAMMA Consortium, with the responsibility of the Research and Innovation group. He has been responsible for IBIMETand LaMMA of several national and European projects. 


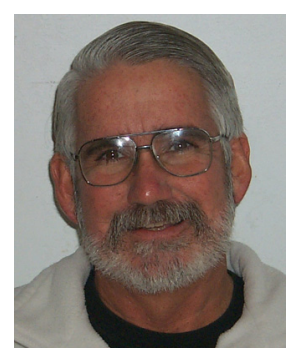

Charles Trees holds his MS from Florida Institute of Technology and his $\mathrm{PhD}$ in oceanography from Texas A\&M University (1985). In 1989 he became adjunct professor at San Diego State University, Center for Hydro-Optics and Remote Sensing (CHORS) and in 2006 combined it with a position as head of the Remote Sensing Branch at the NATO Undersea Research Centre (NURC), now named the Centre for Maritime Research and Experimentation (CMRE). From 2001 to 2003 he was the NASA program manager for ocean biology, color and biogeochemistry in Washington, DC. Since coming to CMRE in 2006 he has developed an optics program to include acquisition of a variety of optical instruments and a fleet (6) of shallow water Slocum gliders equipped with bio-optical sensors. He has lead 3 fully dedicated optical cruises in the Ligurian Sea and coordinates the optical modeling effort developed at CMRE together with international collaborators from the US and European Laboratories. His research interests include phytoplankton photophysiology, optical properties, LIDAR profiling and signal interpretation, and optical modeling for the development and validation of new observation platforms with optical instrumentation.

Biographies and photographs of the other authors not avilable. 